\title{
The New Economy
}

and Beyond

Past, Present and Future

Edited by

Dennis W. Jansen

Texas A\&M University, USA 


\section{Competition policy in network industries: an introduction}

\section{Nicholas Economides*}

\section{INTRODUCTION}

Network industries are a large part of the world economy. A key network industry is telecommunications, providing voice and data services, including the Internet and World Wide Web. Another key network industry is computer software and hardware. These two sectors, telecommunications and computers, have been the engines of fast growth of the world economy. In the news and entertainment sector, network industries include broadcasting and cable television, which in recent years have been reaching into traditional telecommunications services. In transportation, networks include airlines, railroads, roads, and shipping, and the delivery services that 'live' on these, such as the postal service and its competitors. In the financial sector, networks include traditional financial exchanges for bonds, equities, and derivatives, clearing houses, B2B and B2C exchanges, credit and debit card networks, as well as automated transactions banking networks, such as ATM networks.

Besides traditional network industries, many of the features of networks apply to virtual networks. A virtual network is a collection of compatible goods that share a common technical platform. For example, all VHS video players make up a virtual network. Similarly, all computers running Windows 95 can be thought of as a virtual network. Compatible computer software and hardware make up a network, and so do computer operating systems and compatible applications. More generally, networks are comprised of complementary components, so they also encompass wholesale and retail networks, as well as information networks and servers such as telephone Yellow Pages, Yahoo, Google, etc.

Adding to the importance of networks from a public policy point of view is the fact that network industries often provide necessities. Monopolization in such a setting can have significant social and political implications.

There may be a number of anti-competitive concerns in a network industry. The focus of this chapter is the question: Since network industries have 
special common features, are there special competition policy issues arising out of key features of network industries? If yes, what is the framework of the public policies that can be pursued to address these issues?

\section{THE LOGIC OF COMPETITION LAW}

The logic of competition and antitrust law in the United States and the European Union is to guard against restrictions and impediments to competition that are not likely to be naturally corrected by competitive forces. Although some disagree, I will posit that the maximization of efficiency (allocative, productive, and dynamic) is the desired outcome of competition and antitrust law, and that competition is the means of achieving efficiency.

As an alternative to antitrust and competition law, economic regulation have been established in three exceptional cases: (1) for those markets where it is clear that competition cannot be achieved by market forces; (2) where deviation from efficiency is deemed socially desirable; and (3) where the social and private benefits are clearly different. In each of these cases, it is clear that a market without intervention will not result in the desired outcome. In the first case, this is true by the definition of the category. In the second case, markets may lead to efficiency, but society prefers a different outcome and intervention is necessary to achieve this. In the third case, maximization of social surplus does not coincide with maximization of the sum of profits and consumers' surplus because of 'externalities'.

Some key network industries are regulated in at least part or in some aspects. Telecommunications has very significant regulation in both the federal and state level. Railroads, electricity, air and ground transportation are also heavily regulated. Financial exchanges are under 'light' regulation and to a significant extent under self-regulation. In contrast, B2B exchanges, credit card, and banking networks, as well as computers and their virtual networks are almost completely deregulated.

A full discussion of the merits and problems with regulation of each of these network industries is impossible in the context of this chapter. Instead, I will outline the parameters that would necessitate regulation or deregulation based on the broad features of network markets. In future work I will examine the full application of these principles on all network industries. I expect to observe that the principles of economic regulation are not applied equally to all industries, and, in a number of cases, the present regulatory regime is based on historical reasons (political, social, and technological) and cannot be justified based on the application of the economic principles of the present technology. 


\section{SPECIAL FEATURES OF MARKETS WITH NETWORK EFFECTS}

\section{Sources of Network Effects and the Reversal of the Law of Demand}

Many network industries exhibit increasing returns to scale in production: unit (average) cost decreases with increasing scale of production. Often incremental cost is negligible (for example in software). However, these are also features of non-network industries and are not the defining feature of network industries. Thus, increasing returns to scale in production is also not the defining feature of the competition policy issues that are rooted in the existence of networks.

Networks are composed of complementary nodes and links. The crucial defining feature of networks is the complementarity between the various nodes and links. A service delivered over a network requires the use of two or more network components. Thus, network components are complementary to each other.

A common and defining feature of network industries is the fact that they exhibit increasing returns to scale in consumption, commonly called 'network effects'. The existence of network externalities is the key reason for the importance, growth, and profitability of network industries and the New Economy. A market exhibits network effects (or network externalities) when the value to a buyer of an extra unit is higher when more units are sold, everything else being equal.

Network effects arise because of complementarities. In a traditional network, network externalities arise because a typical subscriber can reach more subscribers in a larger network. See Figure 5.1, which depicts a traditional telecommunications network where customers A, B, ..., G are connected to a switch at S. Although goods with 'access to the switch' AS, BS, ..., GS have the same industrial classification and traditional economics would classify them as substitutes, they are used as complements. In particular, when customer A makes a phone call to customer B, he uses both $\mathrm{AS}$ and BS.

In a virtual network, externalities arise because larger sales of components of type $A$ induce larger availability of complementary components $B_{1}, \ldots$, $\mathrm{B}_{n}$, thereby increasing the value of components of type A. See Figure 5.2. The increased value of component A results in further positive feedback. Despite the cycle of positive feedbacks, it is typically expected that the value of component A does not explode to infinity because the additional positive feedback is expected to decrease with increases in the size of the network.

In traditional non-network industries, the willingness to pay for the last unit of a good decreases with the number of units sold. This is called the 
Competition policy in network industries

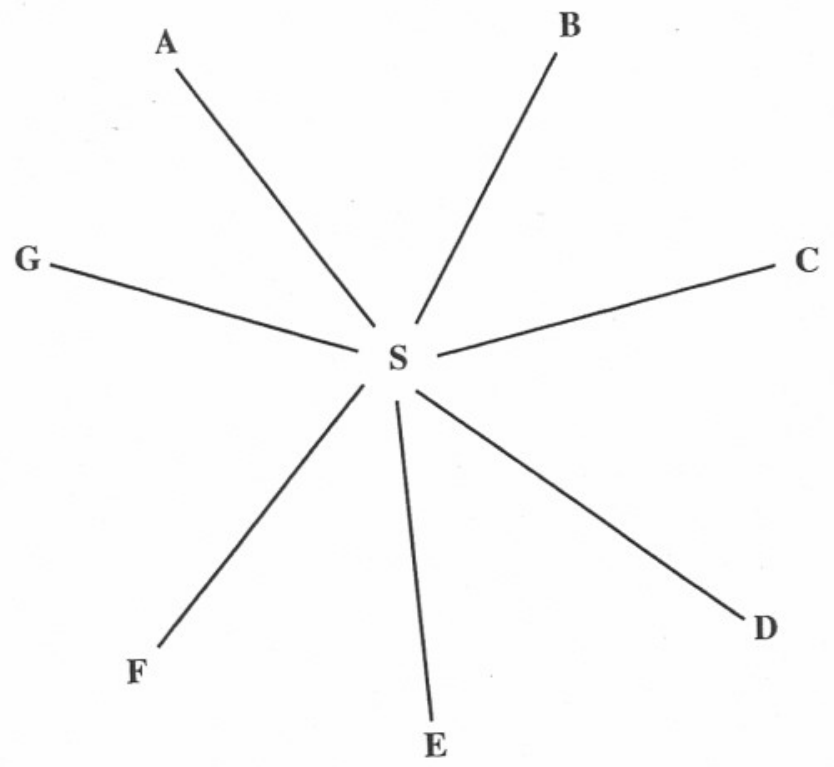

Figure 5.1 A star network

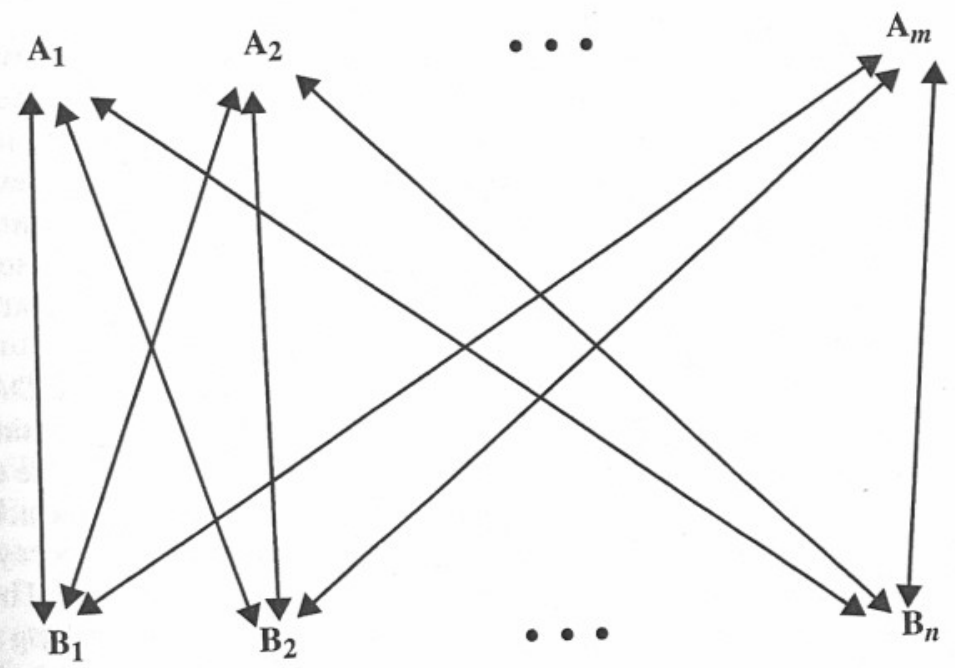

Figure 5.2 A virtual network of complementary goods 
law of demand, and is traditionally considered to hold for almost all goods. ${ }^{1}$ However, the existence of network effects implies that, as more units are sold, the willingness to pay for the last unit may be higher. This means that for network goods, the fundamental law of demand is violated: for network goods, some portions of the curve demand can slope upwards. This means that, for some portions of the demand curve, as sales expand, people are willing to pay more for the last unit.

The law of demand is still correct if one disregards the effects of the expansion of sales on complementary goods. But, as increased sales of a network good imply an expansion in the sales of complementary goods, the value of the last unit increases. Combining the traditional downwardsloping effect with the positive effect due to network expansion can result in a demand curve that has an upward-sloping part.

The key reason for the appearance of network externalities is the complementarity between the components of a network. Depending on the network, the network effect may be direct or indirect. When customers are identified with components, the externality is direct. Consider for example a typical two-way network, such as the local telephone network of Figure 5.1. In this $n$-nodes 2 -way network, there are $2 n(n-1)$ potential goods. An additional ( $n+1$ th) customer provides direct externalities to all other customers in the network by adding $2 n$ potential new goods through the provision of a complementary link (say ES) to the existing links.

In typical one-way networks, the network effect is only indirect. When there are $m$ varieties of component $\mathrm{A}$ and $n$ varieties of component $\mathrm{B}$ as in Figure 5.2 (and all A-type goods are compatible with all of B-type), there are $m n$ potential composite goods. An extra customer yields indirect externalities to other customers, by increasing the demand for components of types A and B and thereby (because of the presence of economies of scale) potentially increasing the number of varieties of each component that are available in the market.

Exchange networks (financial networks such as the NYSE and NASDAQ, commodities, futures, and options exchanges as well as business-to-business 'B2B' exchanges) also exhibit indirect network externalities. There are two ways in which these externalities arise. First, externalities arise in the act of exchanging assets or goods. Second, externalities may arise in the array of vertically related services that compose a financial transaction. These include the services of a broker, bringing the offer to the floor, matching the offer, etc. The second type of externalities are similar to other verticallyrelated markets. The first way in which externalities arise in financial markets is more important.

The act of exchanging goods or assets brings together a trader who is willing to sell with a trader who is willing to buy. The exchange brings 
together the two complementary goods, 'willingness to sell at price $p$ ' (the 'offer') and 'willingness to buy at price $p$ ' (the 'counter-offer') and creates a composite good, the 'exchange transaction'. The two original goods were complementary and each had no value without the other one. Clearly, the availability of the counter-offer is critical for the exchange to occur. Put in terms commonly used in finance, minimal liquidity is necessary for the transaction to occur.

Financial and business-to-business exchanges also exhibit positive size externalities in the sense that the increasing size (or thickness) of an exchange market increases the expected utility of all participants. Higher participation of traders on both sides of the market (drawn from the same distribution) decreases the variance of the expected market price and increases the expected utility of risk-averse traders. Ceteris paribus, higher liquidity increases traders' utility. Thus, financial exchange markets also exhibit network externalities.

As we have noted earlier, network externalities arise out of the complementarity of different network pieces. Thus, they arise naturally in both one- and two-way networks, as well as in vertically-related markets. The value of good $\mathrm{X}$ increases as more of the complementary good $\mathrm{Y}$ is sold, and vice versa. Thus, more of $\mathrm{Y}$ is sold as more $\mathrm{X}$ is sold. It follows that the value of $\mathrm{X}$ increases as more of it is sold. This positive feedback loop seems explosive, and indeed it would be, except for the inherent downward slope of the demand curve.

To understand this better, consider a fulfilled expectations formulation of network externalities. Let the willingness to pay for the $n$th unit of the good when $n^{\mathrm{e}}$ units are expected to be sold be $p\left(n ; n^{\mathrm{e}}\right)$. In this formulation, $n$ and $n^{\mathrm{e}}$ are normalized so that they represent market coverage, ranging from 0 to 1 , rather than absolute quantities. Willingness to pay $p\left(n ; n^{\mathrm{e}}\right)$ is a decreasing function of its first argument because the demand slopes downward. $p\left(n ; n^{\mathrm{e}}\right)$ increases in $n^{\mathrm{e}}$; this captures the network externalities effect, i.e., that the good is more valuable when the expected sales $n^{\mathrm{e}}$ are higher. At a market equilibrium of the simple single-period world, expectations are fulfilled, $n=n^{\mathrm{e}}$, thus defining the fulfilled expectations demand $p(n, n)$.

Figure 5.3 shows the construction of a typical fulfilled expectations demand in a network industry. Each willingness-to-pay curve $p\left(n, n_{i}^{\mathrm{e}}\right)$, $i=1,2, \ldots$, shows the willingness to pay for a varying quantity $n$, given an expectation of sales $n^{\mathrm{e}}=n_{i}^{\mathrm{e}}$. At $n=n_{i}^{\mathrm{e}}$, expectations are fulfilled and the point belongs to $p(n, n)$ as $p\left(n_{i}^{\mathrm{e}}, n_{i}^{\mathrm{e}}\right)$. Thus $p(n, n)$ is constructed as a collection of points $p\left(n_{i}^{\mathrm{e}}, n_{i}^{\mathrm{e}}\right)$. It is reasonable to impose the condition $\lim _{n \rightarrow 1} p(n, n)=0$. This means that, as the market is more and more covered, eventually we reach consumers who are willing to pay very little for the good, despite the fact that they are able to reap very large network 


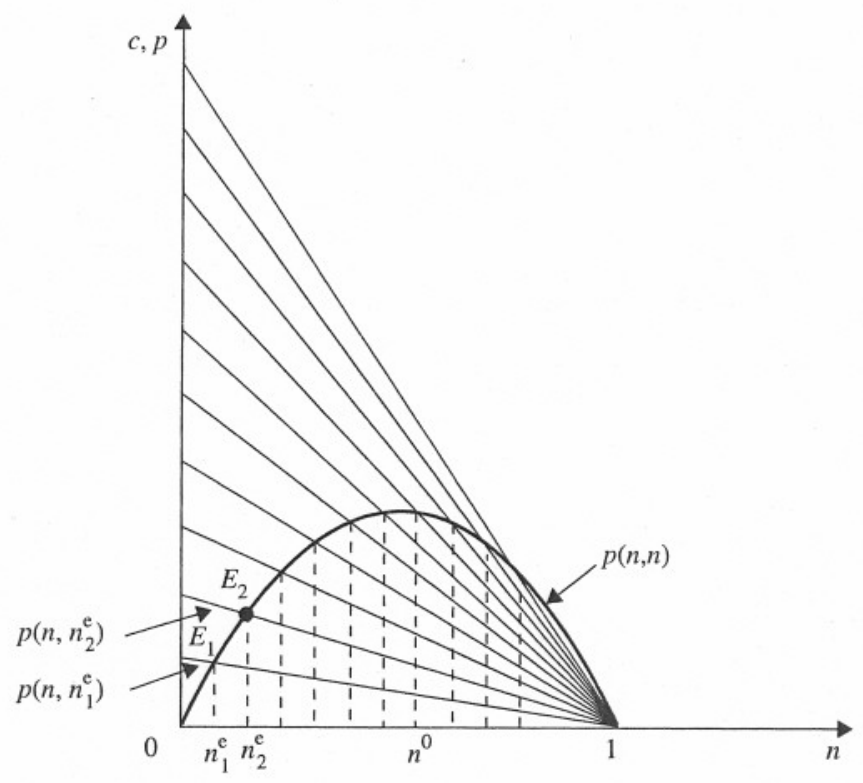

Figure 5.3 Willingness to pay as a function of expected quantity, and the locus of market equilibria where expectations are fulfilled

externalities. It follows that $p(n, n)$ is decreasing for large $n$. In Figure 5.3, the fulfilled expectations demand at quantity zero is $p(0,0)=0$. This means that consumers think that the good has negligible value when its sales (and network effect) are zero. Although this is true for many network goods, some network goods have positive inherent value even at zero sales and no network effects. If the good has an inherent value $k, p(0,0)=k$, the fulfilled expectations demand curve in Figure 5.3 starts at $(0, k)$.

Economides and Himmelberg (1995) show that the fulfilled expectations demand is increasing for small $n$ if either one of three conditions hold:

1. The utility of every consumer in a network of zero size is zero; or

2. There are immediate and large external benefits to network expansion for very small networks; or

3. There is a significant number of high-willingness-to-pay consumers who are just indifferent on joining a network of approximately zero size.

The first condition is straightforward and applies directly to all two-way networks, such as the telecommunications and fax networks where the good has no value unless there is another user to connect to. The other two conditions are a bit more subtle, but commonly observed in networks and 
vertically-related industries. The second condition holds for networks where the addition of even a few users increases the value of the network significantly. A good example of this is a newsgroup on an obscure subject, where the addition of very few users starts a discussion and significantly increases its value. The third condition is most common in software markets. A software application has value to a user even if no one else uses it. The addition of an extra user has a network benefit to other users (because they can share files or find trained workers in the specifics of the application), but this benefit is small. However, when large numbers of users are added, the network benefit can be very significant.

\section{Critical Mass}

When the fulfilled expectations demand increases for small $n$, we say that the network exhibits a positive critical mass under perfect competition. This means that, if we imagine a constant marginal cost $c$ decreasing as technology improves, the network will start at a positive and significant size $n^{0}$ (corresponding to marginal $\operatorname{cost} c^{0}$ ). For each smaller marginal cost, $c<c^{0}$, there are three network sizes consistent with marginal cost pricing: a zero size network; an unstable network size at the first intersection of the horizontal through $c$ with $p(n, n)$; and the Pareto optimal stable network size at the largest intersection of the horizontal with $p(n, n)$. The multiplicity of equilibria is a direct result of the coordination problem that arises naturally in the typical network externalities model. In such a setting, it is natural to assume that the Pareto optimal network size will result.

\section{Features of Markets with Network Effects}

\section{Ability to charge prices on both sides of a network}

There are a number of fundamental properties of network industries that arise out of the existence of network effects.

First, a firm can make money from either side of the network. For example, a telecommunications services provider can charge subscribers when they originate calls or when they receive calls or for both. ${ }^{2}$ When a network consists of software clients and servers, both provided by the same firm, the firm can use the prices of the client and server software to maximize the network effect and its profits. For example it can distribute the client at marginal cost (free) and make all its profits from the server. In a similar vein, Adobe distributes the 'Acrobat Reader' free while it makes its profits from the 'Acrobat' product that allows the creation of files that can be read by the Acrobat Reader. The availability of prices on both sides of the network allows for complex pricing strategies, and, depending on the 
dynamics and market shares in the two sides of the market, can be used strategically to enhance and leverage a firm's strong strategic position on one side of the network.

\section{Externalities internalized or not}

Second, in network industries, the additional subscriber/user is often not rewarded for the benefit that he/she brings to others by subscribing. Hence typically there are 'externalities', i.e., benefits not fully intermediated by the market. However, firms can use price discrimination to make favorable terms available to large users to maximize their network effect contribution to the market. For example, a large customer in a financial market can be given a very low price to be compensated for the positive network effect it brings to the market. ${ }^{3}$

\section{Fast network expansion}

Third, generally, the pace of market penetration (network expansion) is much faster in network industries than in non-network industries. In the earlier discussion on critical mass, we saw that, in a one-period model, as unit cost decreases, the network starts with significant market coverage. In the presence of frictions and imperfectly elastic supply, the network expansion is not instantaneous from 0 to $n^{0}$ but rather is a very fast expansion following and S-shaped curve, as seen in Figure 5.4. This figure compares the market share expansion of a new good (diffusion) in presence (delta $=1$ ) and absence (delta $=0)$ of network effects. The self-reinforcing nature of network effects leads to a much faster expansion when they are present. ${ }^{4}$

\section{Inequality of market shares and profits}

Fourth, markets with strong network effects where firms can chose their own technical standards are 'winner-take-most' markets. In these markets, there is extreme market share and profits inequality. The market share of the largest firm can easily be a multiple of the market share of the second largest, the second largest firm's market share can be a multiple of the market share of the third, and so on. This geometric sequence of market shares implies that, even for a small number of firms $n$, the $n$th firm's market share is tiny. At equilibrium, there is extreme market share and profits inequality. ${ }^{5}$

The reason for the inequality is straightforward. A firm with a large market share has more complementary goods and therefore its good is more valuable to consumers. Good examples of this are PC operating systems market and specific software applications markets.

To understand the extent of market share, price, and profits inequality in network industries, we provide results from Economides and Flyer (1998). As a benchmark, they assume that all firms produce identical products, 


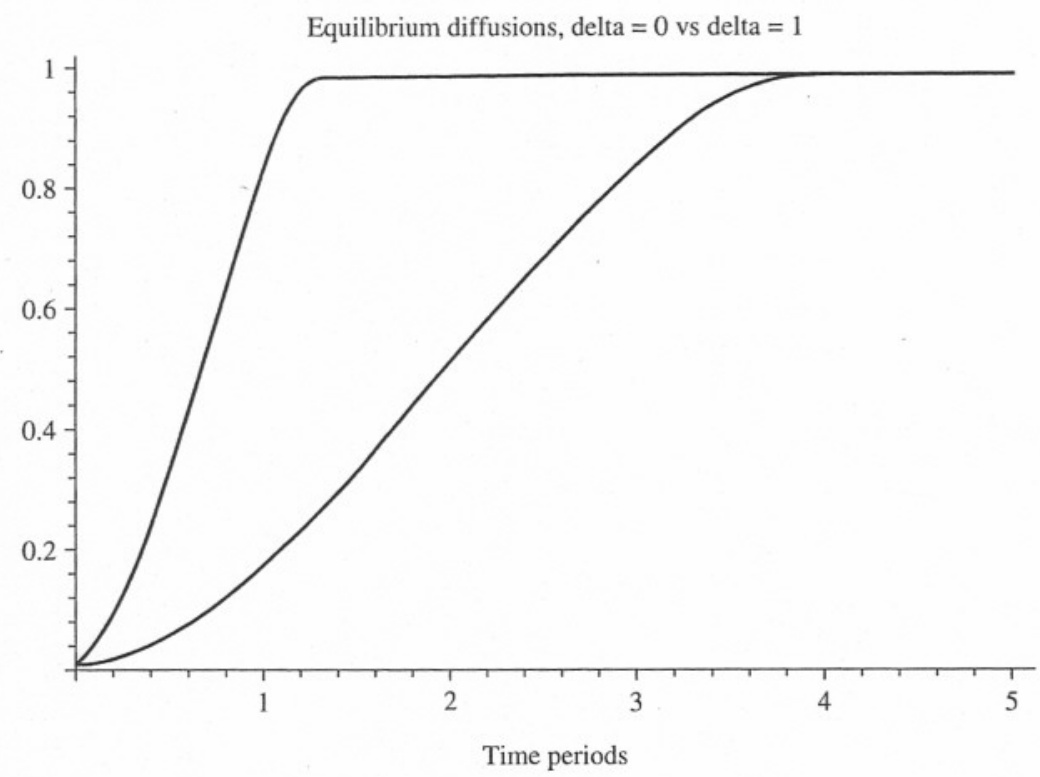

Figure 5.4 Diffusion in the presence of network effects (delta $=1$ ) and in their absence (delta $=0)$

except for whatever quality is added to them by network externalities. They also assume that no firm has any technical advantage in production over any other with respect to any particular platform and that there are no production costs. We consider here only the extreme case of 'pure network goods' where there is no value to the good in the absence of network externalities. The summary of the equilibria under total incompatibility (which can be enforced when firms have proprietary standards) is in Tables 5.1 and 5.2. Firm \#1 has the largest sales, firm \#2 is the second largest, etc.

Even with no fixed costs and an infinite number of firms, the HerfindahlHirschman index $(\mathrm{HHI})=0.464$, which corresponds to between two and three firms of equal size.

The market equilibria exhibit extreme inequality. The ratio of outputs of consecutive firms is over 2.6. Ratios of prices of consecutive firms is at least 7 . The ratio of profits of consecutive firms is about 20 . This means that a firm has about 38 per cent of the sales of the immediately larger firm, can charge only 15 per cent of the price of the next larger firm, and receives only 5 per cent of the profits of the immediately larger firm. Entry after the third firm has practically no influence on the output, prices, and profits of the top three firms as well as the consumers' and producers' surplus. From the fourth one on, firms are so small that their entry hardly influences the market. 
Table 5.1 Quantities, market coverage, and prices under incompatibility

\begin{tabular}{lcccccccc}
\hline $\begin{array}{l}\text { Number } \\
\text { of firms }\end{array}$ & $\begin{array}{c}\text { Sales of } \\
\text { largest } \\
\text { firm } \mathrm{q}_{1}\end{array}$ & $\begin{array}{c}\text { Sales of } \\
\text { second } \\
\text { firm } \mathrm{q}_{2}\end{array}$ & $\begin{array}{c}\text { Sales of } \\
\text { third } \\
\text { firm } \mathrm{q}_{3}\end{array}$ & $\begin{array}{c}\text { Market } \\
\text { coverage } \\
\sum_{j=I}^{I} \mathrm{q}_{j}\end{array}$ & $\begin{array}{c}\text { Price of } \\
\text { largest } \\
\text { firm } \mathrm{p}_{1}\end{array}$ & $\begin{array}{c}\text { Price of } \\
\text { second } \\
\text { firm } \mathrm{p}_{2}\end{array}$ & $\begin{array}{c}\text { Price of } \\
\text { third } \\
\text { firm } \mathrm{p}_{3}\end{array}$ & $\begin{array}{c}\text { Price of } \\
\text { smallest } \\
\text { firm } \mathrm{p}_{I}\end{array}$ \\
\hline 1 & 0.6666 & & & 0.6666 & 0.222222 & & & $2.222 \mathrm{e}-1$ \\
2 & 0.6357 & 0.2428 & & 0.8785 & 0.172604 & 0.0294 & & $2.948 \mathrm{e}-2$ \\
3 & 0.6340 & 0.2326 & 0.0888 & 0.9555 & 0.170007 & 0.0231 & 0.0035 & $3.508 \mathrm{e}-3$ \\
4 & 0.6339 & 0.2320 & 0.0851 & 0.9837 & 0.169881 & 0.0227 & 0.0030 & $4.533 \mathrm{e}-4$ \\
5 & 0.6339 & 0.2320 & 0.0849 & 0.9940 & 0.169873 & 0.0227 & 0.0030 & $7.086 \mathrm{e}-5$ \\
6 & 0.6339 & 0.2320 & 0.0849 & 0.9999 & 0.169873 & 0.0227 & 0.0030 & $9.88 \mathrm{e}-11$ \\
7 & 0.6339 & 0.2320 & 0.0849 & 0.9999 & 0.169873 & 0.0227 & 0.0030 & 0 \\
\hline
\end{tabular}

Note: $\mathrm{q}_{1}$ indicates sales of firm 1, where the sum of sales of all firms is normalized to be less than or equal to one. Prices are in dollars. The $i$ th firm produces quantity $\mathrm{q}_{i}$ at price $\mathrm{p}_{i}$, and firms are ordered in decreasing quantity so that $q_{1}>q_{2}>q_{3}$, etc.

Source: Economides and Flyer (1998).

Table 5.2 Profits, consumers' and total surplus under incompatibility

\begin{tabular}{|c|c|c|c|c|c|c|c|}
\hline $\begin{array}{l}\text { Number } \\
\text { of firms } \\
I\end{array}$ & $\Pi_{1}$ & $\Pi_{2}$ & $\Pi_{3}$ & $\begin{array}{c}\text { Profits of } \\
\text { last firm } \\
\Pi_{1}\end{array}$ & $\begin{array}{c}\text { Total } \\
\text { industry } \\
\text { profits } \\
\sum_{j=i}^{I} \Pi_{j}\end{array}$ & $\begin{array}{c}\text { Consumers' } \\
\text { surplus CS }\end{array}$ & $\begin{array}{c}\text { Total } \\
\text { surplus TS }\end{array}$ \\
\hline 1 & 0.1481 & & & 0.1481 & 0.1481 & 0.148197 & 0.29629651 \\
\hline 2 & 0.1097 & $7.159 \mathrm{e}-3$ & & $7.159 \mathrm{e}-3$ & 0.1168 & 0.173219 & 0.29001881 \\
\hline 3 & 0.1077 & $5.377 \mathrm{e}-3$ & $3.508 \mathrm{e}-4$ & $3.508 e-4$ & 0.1135 & 0.175288 & 0.28878819 \\
\hline 4 & 0.1077 & $5.285 \mathrm{e}-3$ & $3.096 \mathrm{e}-4$ & $1.474 \mathrm{e}-5$ & 0.1132 & 0.175483 & 0.28868321 \\
\hline 5 & 0.1077 & $5.281 \mathrm{e}-3$ & $2.592 \mathrm{e}-4$ & $8.44 \mathrm{e}-7$ & 0.1132 & 0.175478 & 0.28867817 \\
\hline 6 & 0.1077 & $5.281 \mathrm{e}-3$ & $2.589 \mathrm{e}-4$ & $1.18 \mathrm{e}-14$ & 0.1132 & 0.175478 & 0.28867799 \\
\hline 7 & 0.1077 & $5.281 \mathrm{e}-3$ & $2.589 \mathrm{e}-4$ & 0 & 0.1132 & 0.175478 & 0.28867799 \\
\hline
\end{tabular}

Note: Profits of firm 1 are $\Pi_{1}$. All variables are in dollars. Subscripts indicate firms; П signifies profits.

Source: Economides and Flyer (1998).

\section{Monopoly may maximize total surplus}

Fifth, in industries with significant network externalities, under conditions of incompatibility between competing platforms, monopoly may maximize social surplus. This is because, when strong network effects are present, a very large market share of one platform creates significant network benefits for this platform which contribute to large consumers' and producers' surpluses. 
It is possible to have situations where a breakup of a monopoly into two competing firms of incompatible standards reduces rather than increases social surplus because network externalities benefits are reduced. This is because de facto standardization is valuable, even if done by a monopolist.

In the Economides-Flyer model, although consumers' surplus is increasing in the number of active firms, total surplus is decreasing in the number of firms. That is, the more firms in the market, the lower is total welfare. This remarkable result comes from the fact that when there are fewer firms in the market there is more coordination and the network effects are larger. As the number of firms decreases, the positive network effects increase more than the dead weight loss, so that total surplus is maximized at monopoly! Thus, total surplus is highest at monopoly while consumers' surplus is lowest at monopoly. This poses an interesting dilemma for antitrust authorities. Should they intervene or not? In non-network industries, typically both consumers' and total surplus are lowest at monopoly. In this network model, maximizing consumers' surplus would imply minimizing total surplus.

Compared to the market equilibrium under compatibility, the incompatibility equilibrium is deficient in many dimensions. Consumers' and total surplus are higher under compatibility; the profits of all except the highest production firm are lower under incompatibility; and prices are lower under compatibility except for duopoly.

\section{No anti-competitive acts are necessary to create market inequality}

A sixth implication of network effects is that, because inequality is natural in the market structure of network industries, there should be no presumption that anti-competitive actions are responsible for the creation of market share inequality or very high profitability of a top firm. Thus, no anti-competitive acts are necessary to create this inequality. The 'but for' benchmark against which anti-competitive actions in network industries are to be judged should be not be 'perfect competition' but an environment of significant inequality and profits.

\section{In network industries, free entry does not lead to perfect competition}

A seventh implication of network effects is that, in network industries, free entry does not lead to perfect competition. In a market with strong network effects, once a few firms are in operation, the addition of new competitors, even under conditions of free entry, does not change the market structure in any significant way. Although eliminating barriers to entry can encourage competition, the resulting competition may not significantly affect market structure. This implies that, in markets with strong network effects, antitrust authorities may not be able to significantly affect market structure 
by eliminating barriers to entry. See earlier example where the addition of the fifth firm hardly changes the output of the first four firms.

The remarkable property of the incompatibility equilibrium is the extreme inequality in market shares and profits that is sustained under conditions of free entry. Antitrust and competition law have placed a tremendous amount of hope on the ability of free entry to spur competition, reduce prices, and ultimately eliminate profits. In network industries, free entry brings into the industry an infinity of firms but it fails miserably to reduce or to flatten the distribution of market shares. Entry does not eliminate the profits of the high production firms. And, it is worth noting that, at the equilibrium of this market, there is no anti-competitive behavior. Firms do not reach their high output and market domination by exclusion, coercion, tying, erecting barriers to entry, or any other anti-competitive behavior. The extreme inequality is a natural feature of the market equilibrium.

At the long-run equilibrium of this model, free entry is present and an infinity of firms have entered, but the equilibrium is far from competitive. No anti-competitive activity has led firms to this equilibrium. Traditional antitrust intervention cannot accomplish anything because the conditions such intervention seeks to establish already exist in this market. Unfortunately the desired competitive outcome does not.

Can there be an improvement over the market incompatibility equilibrium? Yes, a switch to the compatibility equilibrium which has higher consumers' and total surpluses for any number of firms. Is it within the scope of competition law to impose such a change? It depends. Firms may have a legally protected intellectual property right that arises from their creation of the design of the platform. Only if anti-competitive behavior was involved, can the antitrust authorities clearly intervene.

\section{Imposing a 'competitive' market structure is likely to be counterproductive}

The eighth implication of network effects is that antitrust interventions may be futile. Because 'winner takes most' is the natural equilibrium in these markets, attempting to superimpose a different market structure (say one of all firms having approximately equal market shares), may be both futile and counterproductive.

\section{Nature of competition is different in network industries}

A ninth implication of the network effects is that competition for the market takes precedence over competition in the market. The fact that the natural equilibrium market structure in network industries is winner-take-most with very significant market inequality does not imply that competition is weak. Competition on which firm will create the top platform and reap most of the benefits is, in fact, very intense. In network industries, there is typically a very 
intense race to be the dominant firm. In network industries, we often observe Schumpeterian races for market dominance.

A good recent example of Schumpeterian competition is the competition among dot-coms in 1999-2000. As explained earlier, economic models imply very high valuation of the dominant firm compared to other firms in the same network industry. The same perception prevailed in Wall Street. During that period, dot-com firms advertised very intensely and subsidized consumers to be able to achieve the coveted dominant position in the market. The easy availability of capital for dot-coms at the time made it easy to observe their behavior as they 'burned' almost all the cash they had to get the top market share. Many of the dot-coms failed because demand for their services was much lower than predicted or because of flaws in their business models. However, all the successful dot-coms, such as eBay, Amazon, and Yahoo, also followed this strategy.

Generally, in network industries, the costs of entry may be higher but the rewards of success may also be higher compared to non-network industries.

\section{Path dependence}

A tenth implication of network effects is the importance of path-dependence. Path-dependence is the dependence of a system or network on past decisions of producers and consumers. For example, the price at which a VHS player can be sold today is path-dependent because it depends on the number of VHS players sold earlier (the installed base of VHS players). The existence of an installed base of consumers favors an incumbent. However, competitors with significant product advantages or a better pricing strategy can overcome the advantage of an installed base.

For example, in the market for video players, VHS overcame Beta after six years of a higher installed base by Beta. This was an implication of:

1. Sony's mistakes in disregarding network externalities and not licensing the Beta format;

2. Matsushita's widespread licensing of VHS;

3. The fact that one low-end low-price VHS player can contribute as much to the network effect as a high-end high-price Beta player.

In the Beta/VHS case, it is clear that Sony mistakenly disregarded the network effects that arose from the availability of rental tapes of prerecorded movies. The main function of video recorders was originally thought to be 'time delay' in watching material recorded from the TV. The pre-recorded market emerged later, first as a market where movies were sold, and later as a movies rental market. The emergence of markets for 'movies for sale' and 'movies for rent', which had to be recorded in particular format, 
created a significant complementary good for Beta and VHS players. The significant cost of physical distribution of tapes throughout the country and the costs of carrying a significant inventory of titles made the choice of what movies to bring and in what format crucially dependent on present and forecast demand which was closely correlated with the present and forecast installed base of video players in each format. Thus, although network effects and path dependence played a crucial role in determining the fate of Beta, the outcome was far from predetermined. Early, more aggressive licensing of the Beta format by Sony or the early promotion of low-end Beta players could have reversed the demise of the Beta format. ${ }^{6}$

\section{COMPETITION POLICY ISSUES IN NETWORK INDUSTRIES}

\section{One-sided Bottlenecks}

Interconnection issues in telecommunications, railroads, airline, and other transportation networks are very common. Often one company has exclusive control of part of the network, which is required by others to provide services. We call this network part 'a bottleneck.' Generally, bottlenecks can be divided into two categories: one-sided and two-sided. A one-sided bottleneck is monopolized by a firm and this firm does not require the use of a different bottleneck. An example of such a bottleneck is shown as link AB in Figure 5.5. An example of such a bottleneck is the connection of local service telecommunications subscribers to a switch. This is typically called 'the last mile', and often called 'the local loop'. After the 1984 breakup of AT\&T, the local loop has been monopolized by the local exchange carrier, typically a Regional Bell Operating Company ('RBOC') or GTE (General Telephone and Electronics). The local loop is a required input in the production of

1

A
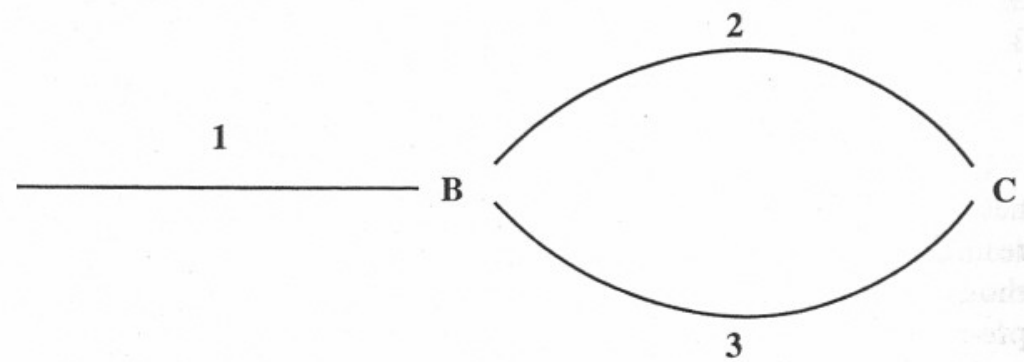

Figure 5.5 A one-sided bottleneck 
long-distance services, and typically long-distance companies do not have a comparable local loop. Similarly, such a one-way bottleneck can arise when a firm monopolizes a railroad track such as $\mathrm{AB}$. In telecommunications, the local exchange bottleneck has traditionally resulted in high prices for use of the bottleneck to originate ('access origination') or terminate calls ('access termination').

The potential anti-competitive consequences of a one-sided bottleneck are obvious, and have been understood since the early days of the telecommunications network when AT\&T enjoyed a monopoly in long distance (say here $\mathrm{AB}$ ) but faced competition in local markets. In the context of Figure 5.5, the early AT\&T was in possession of links 1 (long distance) and 2 (local), but did not allow an independent firm which possessed link 3 to interconnect at $B$ and provide part of the long-distance service CBA. For over two decades in the beginning of the twentieth century, AT\&T refused to interconnect independent local telecommunications companies to its long-distance network, unless they became part of the Bell System, which essentially meant unless they were acquired. ${ }^{7}$

The early AT\&T foreclosure of independents through a refusal to interconnect shows the importance of complementarities in networks and the way that companies can leverage dominance in one market to create dominance in a market for complementary goods, especially when the complementary good requires the monopolized input (to provide a final service). In this case, AT\&T monopolized long distance and was able to leverage its position in long distance (through the refusal to interconnect of independent locals) and gain a dominant position in local telecommunications markets throughout the country.

The continued foreclosure of the independents by AT\&T and its 'refusal to deal' with them caused regulation to be established at the state and Federal levels in the 1930s. The 1934 Federal Communications Act ('1934 Act') imposed mandatory interconnection in an attempt to stop the foreclosure of independents and stabilized the market share of local lines held by AT\&T. However, at that point AT\&T's market share of local lines had already reached close to the 89 per cent that AT\&T had at its breakup in 1981 .

A major revision of the 1934 Act, the Telecommunications Act of 1996 ('1996 Act') mandates interconnection of all public switched telecommunications networks at any technically feasible point. The 1996 Act and similar European Union regulations attempt to solve the problem of the monopolization of the key parts of local telecommunications network. They impose unbundling of the network and forced lease to entrants of some of the monopolized parts of the network, including the local loop. The goal is to make mix and match entry strategies feasible for local voice telephone service as well as broadband Internet access through DSL that 
utilizes high frequencies transmission though copper local loops. Thus, they mandate alternative access prices for unbundled parts of the network (unbundled network elements 'UNEs') at cost-based prices. The Federal Communications Commission (FCC) and state Public Utilities Commissions (PUCs) accepted the view that lease prices should be based on forward-looking costs rather than on historical, accounting, or embedded costs (which was favored by RBOCs). In setting prices for unbundled network elements, the FCC and state PUCs also rejected the relevance of prices based on private opportunity cost, such as the 'Efficient Components Pricing Rule', ('ECPR'). Such rules derive prices for components from the monopoly end-to-end prices. Thus, the ECPR and its varieties would guarantee the monopolist's profits despite market structure changes in the markets for components that are used to create final services (see Economides and White 1995; Economides 2003). The 1996 Act also imposes a number of rules to prevent anti-competitive actions in telecommunications, such as number portability, mandatory resale of services, transparency, non-discrimination, etc. A full discussion of these rules can be found at Economides (1999). Still, the 1996 Act missed opportunities to define technical standards. Unfortunately, legal maneuvers by the incumbent local exchange carriers and high prices for the unbundled network elements considerably delayed significant entry into local telecommunications markets.

\section{Two-sided Bottlenecks}

In a two-sided bottleneck, each of two firms is monopolist, each with a different bottleneck, and each firm requires the other's bottleneck to produce its output. For example, suppose there are two local telephone companies, each customer subscribes only to one local telephone company, and each company requires the other's network to complete calls. This could be represented in Figure 5.5 with the second link $\mathrm{BC}$ (number 3 ) removed, and considering $\mathrm{AB}$ to belong to firm 1, $\mathrm{BC}$ to belong to firm 2, firm 1 selling service $\mathrm{ABC}$ and firm 2 selling service $\mathrm{CBA}$. In the context of this example, each of firms 1 and 2 buys access termination from the other. If each firm $i=1,2$, sells both services ABC and CBA, then each firm buys both access origination and access termination from the other.

Many of the issues of traditional bottlenecks have been dealt with by regulation in the United States and the European Union. In monopolized oneway bottlenecks, such as access origination and termination used in the creation of long-distance calls, there has been a tendency to decrease the regulated prices, but prices are still high. In the two-way bottleneck of access used in the creation of local calls by competing local exchange carriers, the 
Telecommunications Act of 1996 ('1996 Act') imposes cost-based reciprocal fees and allows the possibility of 'bill and keep', i.e., zero prices. If cost-based reciprocal compensation were not the rule, and firms were able to set termination at profit maximizing levels, Economides et al. (1996a, 1996b), have shown that a large network will try to impose very high termination charges on an opponent small network so that no calls terminate from the small network to the large one. Without the possibility of such across-networks calls, a small network will only be able to provide within-the-network calls, and, being small, will add little value to potential subscribers. As a consequence, large networks are able to provide more value to subscribers, and the small network is foreclosed. Starting from a regime of large local incumbent and a small local entrant, the large incumbent can set up termination access fees so that the entrant is driven out of the market. ${ }^{8}$

In summary, in the absence of specific regulatory rules, two-sided bottlenecks can lead to foreclosure of competitors, even when each firm requires use of the bottleneck of the other to complete calls or provide a service.

\section{Market Power Creation Specific to Networks: Technical Standards}

The early AT\&T refusal to deal (interconnect) with independents (and with interconnected networks of independents) can arise in milder terms when a firm $X$ that has a significant position in its industry insists that firms that provide products $\mathrm{Y}$ that are complementary to $\mathrm{X}$ do not also provide them for any competitor of X. For example, in the mid-1980s Nintendo refused to allow third-party games (software) to play on its game console (hardware) unless the software manufacturers agreed not to write a similar game for two years for competing game systems. Faced with this condition imposed by Nintendo, software developers had to make a choice to either write a game for Nintendo or for the competing platforms of Atari and Sega. Clearly this restriction reduced the potential revenue of a game developer who would like, for a small additional cost, to port its game to the alternative systems. But, also, more important, the restriction forced developers to predict which game system would have higher sales, and create software just for this system. Thus, Nintendo used the dominance of the game market at that point in time to coerce developers to write software just for its platform, and thereby increased the value of the Nintendo virtual network (of hardware and software). Nintendo abandoned this requirement under an antitrust challenge.

Because of the extreme inequality of market shares, prices, and profits in a network industry, restriction to the installed base of a firm in a network industry can be very detrimental since it can push a firm to a lower rank with significantly lower profits, or, in extreme cases, push a firm to such a low market share that it has closed down because it cannot recover fixed costs. 
Another example from the computing industry illustrates a situation of market power creation specific to networks. Suppose that firm A chooses to make its product $\mathrm{A}$ incompatible with the products of other firms that perform similar functions, and it also subsidizes firms that produce complementary goods B to its product A. ${ }^{9}$ Alternatively, we may assume that firm A subsidizes its own division that sells complementary goods B. As a result:

1. The value of firm A's product increase;

2. The entry hurdle of firm A's rivals increases;

3. There is possible creation of market power.

Firm A's defense will be that its actions are pro-competitive since their primary cause is the enhancement of value of product A. For the point of view of A's competitors, the actions of A look very much anti-competitive since the abundance of complementary goods B for product A puts them at a competitive disadvantage.

Note that the existence of incompatibility is a necessary condition for possible creation of market power. Moreover, the key to increasing social welfare is a potential move to compatibility. That is, assuming that innovation and product availability would not be reduced, the best of all worlds is to have public standards and full compatibility. However, it is very difficult for US antitrust authorities to intervene and/or define standards.

Besides the use of technical standards, firms can also use bundling and other pricing strategies as well as non-price discrimination strategies to leverage market power across markets.

In networks, as in other settings, there are potentially anti-competitive issues arising from the possibility of vertical integration and the behavior of vertically integrated firms. These may include, first, the bundling of components through vertical integration contracts, or manipulation of technical standards so that an entrant will not be able to enter in only one of the components markets, but will have to enter in both. Often firms have expertise or a technical advantage in only one component, and would like to enter only in the market for that component. An incumbent can strategically alter the market environment through acquisition or contract so that the entrant can only be successful if it enters more than one market. This increases the financial hurdle for an entrant, and it also forces it to sell components where it does not have expertise. Thus, it makes it more likely that entry will not occur.

A vertically integrated firm can also use discrimination in prices charged to a subsidiary compared to prices charged to a downstream competitor, or discrimination in quality provided to a subsidiary compared to quality 
provided to a downstream competitor, that is raising rivals' costs. These issues are discussed in more detail in Economides (1998).

Firms in network industries can also use a variety of ways to manipulate technical standards in joint ventures to achieve market power. The issue of market power also arises in 'aftermarkets', where consumers are 'locked in' to a durable good or a service that arises out of commitments of a durable nature. For example, in an important case that reached the Supreme Court, Kodak refused to supply parts to independent firms that serviced Kodak photocopiers. Although one could argue that there was significant competition in the market for new photocopiers and Kodak did not have a dominant position in that market, once customers had bought a Kodak photocopier, they were locked in, and faced significant costs to buy a new photocopier of a different brand. So, Kodak's actions could be anti-competitive in the 'aftermarket' for repair services of consumers who have already bought Kodak photocopiers. A similar case of anti-competitive actions can be made in aftermarkets where consumers are locked-in by having made an investment in a durable good that is incompatible with other comparable durable goods, or are locked-in in other ways. For example, consumers without number portability in wireless cellular and PCS markets may be locked-in the service of a particular provider or network.

\section{B2B and Other Exchanges Issues}

The world of business to business exchanges lacks the regulation of traditional financial and commodity exchanges. Many proposed B2B exchanges are run by the firms that also are trading. For example, Enron was proud of the fact that it was participating as a trading party in B2B exchanges that it organized and ran. Such a situation would be strictly prohibited in traditional financial and commodity exchanges because of the possibility that the organizer of the exchange would take advantage of the information created in the trading process to fashion privately beneficial trades. In another example, COVISINT, an exchange for automobile parts organized by automobile manufacturers has been accused of acting to consolidate the monopsony power of car manufacturers. In general, B2B exchanges can provide substantial benefits by consolidating trades, increasing market liquidity, improving standardization, and reducing search costs. ${ }^{10}$ But B2B exchanges also have the potential of creating significant antitrust issues.

\section{Dynamic Efficiency Issues}

The world of networks and dynamic effects brings to the forefront the fact that behavior that exhibits static efficiency may lack dynamic inter-temporal 
efficiency. The possibility exists of a lock-in to a technology and a path which, when decisions taken in every period, looks optimal given past decisions, but is sub-optimal if earlier investment decisions had been delayed and all the decisions were taken at once. In a world with network effects a lock-in in an inferior technology can easily occur as firms (and countries) find it more desirable to invest further in the technology in which they already invested. This can occur under perfect competition. The problem can easily become much more important under oligopoly, as firms race to become the dominant firm, given the importance of dominance in a network industry.

\section{Innovation Issues}

An important antitrust issue is the speed of innovation in a network industry as affected by strategic decisions of firms and potentially anticompetitive actions. The effects of actions on innovation are important because innovation affects the welfare of future consumers, and this should be taken into consideration in an antitrust action. The difficulty in dealing with innovation issues in an antitrust action arises from the fact that the efficiency and intensity of innovation in monopoly compared to perfect competition and oligopoly are open questions in economics. Thus, it is very hard to make general statements on innovation in an antitrust context.

\section{Criteria to be Used for Antitrust Intervention in Network Industries}

When an antitrust intervention is considered in a network industry, a number of considerations that arise out of the nature of network industries have to be taken into account. These are explained in detail in earlier sections. First, the benchmark of the 'but for' world that should be considered should be a network industries equilibrium with significant inequality, rather than a perfectly competitive equilibrium. Second, competitors' harm should not be a sufficient reason for intervention. The right question is, 'were consumers (past, present, future) harmed by specific actions?' Third, uncertainty should be taken into account, and caution should be used in guessing how a high-tech industry would have evolved but for the anti-competitive action(s). Fourth, it is possible that monopoly may maximize total surplus. Fifth, that it will not be possible to sustain a long-term equalmarket-shares equilibrium, and a short-term equal-market-shares equilibrium may have low total surplus. Sixth, path dependence and the value of the installed base are limited by Schumpeterian competition, and upheavals are not uncommon in network industries. Seventh, especially in software industries, the extent and functionality of products is flexible. This can help 
an incumbent because it can expand the functionality of its product, but can also help its rivals as they may incorporate functionalities of the incumbent's product in theirs.

\section{Criteria to be Used for Remedies}

When a remedies phase is reached, a liability finding has already been made. The objective of remedies is to stop practices that were found to be illegal, prevent the recurrence of such practices, and deal with any recurring threat posed by such practices.

Any intervention by antitrust authorities creates a disruption in the workings of markets. The objective of the remedial relief is to accomplish the objectives mentioned in the previous paragraph without damaging efficient production and competition in the market. The potential damage that antitrust intervention can produce is larger when it is applied to an industry with fast technological change, where leaps to new and more efficient technologies are expected, while the specific nature of the future winning technology is unknown. Often, it is plainly difficult to predict future winning technologies and therefore it is very hard to fashion an antitrust remedy with an accurate prediction of its effect on industry structure and competition a few years down the road. Of course, this uncertainty is multiplied when the remedy creates a significant intervention in the industry. Therefore, lacking the knowledge of the effects of their actions, it is in the public interest that antitrust authorities and courts avoid very extensive intervention in industries with fast technological change. It is best to intervene only to the extent that (1) intervention reverses the effects of actions for which liability was established; and (2) the effects of the intervention are predictable.

The existence of network effects has crucial implications for market structure and the ability of antitrust authorities to affect it. Even in the absence of anti-competitive acts, the existence of strong network effects in a market, can result in very significant inequalities in market shares and profits. The resulting equilibrium market structure can be called a 'natural oligopoly' where very few firms dominate the market. The structural features of natural oligopoly for software markets cannot be altered by antitrust intervention without very significant losses for society. The very nature of markets with network effects implies that the ability of antitrust authorities to alter market stricture in such industries is limited, as discussed above.

As an alternative to antitrust and competition law, economic regulation can and has been established in three exceptional cases: (1) for those markets where it is clear that competition cannot be achieved by market forces; (2) where deviation from efficiency is deemed socially desirable; and (3) where the social and private benefits are clearly different, since in each of 
these cases, it is clear that a market without intervention will not result in the desired outcome. I will leave case (2) aside, since a discussion of it would lead us to a detailed discussion of specific industries. The requirements for case (3) are typically met in many network industries, since expansion of the network creates network effects that are typically not fully internalized by markets. However, it would be foolish to advocate regulation as the standard solution in network industries because of the existcnce of network effects. Often, a much smaller intervention, such as subsidization of the network to help network effects will be enough.

In case (1), where it is clear that competition and its benefits cannot be achieved by market forces, regulation may be a solution. The significant advantage of industry-specific regulation is that it can be tailored to the specifics of the industry, and specify rules on pricing and availability of particular products and services. Regulators, such as the FCC, also have staffs that can provide impartial technical advice that would be unavailable to a court.

However, regulation has a number of drawbacks. First, it is best suited for industries with well defined and not changing products and services. With stable product definitions, rules can be devised and specific pricing can be implemented if necessary. Second, as a corollary to the first observation, regulation is not well suited in industries with high technological change and frequently changing product definitions. Moreover, in an industry with fast technical progress, regulation can be used by the regulated companies to keep prices high, as exemplified by telecommunications regulation. Third, often regulators are very close to the interests of the regulated parties rather than to the interests of the public. Fourth, experience has shown that often regulators are not well informed about key variables as well as changes in the industry. Fifth, regulators at both the state and federal levels are under pressure and influence by both the executive and the legislative part of government, and cannot be as impartial as a court. These drawbacks can create significant surplus loss due to regulation.

In summary, regulation should be used sparingly in industries with stable products, if it is clear that antitrust action has failed, and keeping in mind that regulation can also cause a significant surplus loss.

\section{CONCLUSION}

This chapter is a start of an in-depth discussion of public policy in network industries. I believe that it is fair to say that the legal system does not yet have a framework for analysis of competition policy issues in network industries. This was to a large extent exemplified in United States v. Microsoft. I will not 
go into the details of this case, but will use it as an example of a case that failed to create such a framework..$^{11}$

The Microsoft case has certainly been the most important antitrust case of the 'New Economy' this far. Unfortunately, its legal battle was fought to a very large extent without the use of the economics tools discussed above that are at the foundation of the New Economy and were key to the business success of Microsoft. There are a number of reasons for this. First, legal cases are often created and filed before an economist is found who will create the appropriate economic model to support the case. Second, the economic theory of networks is so inadequate and unsettled that there is no commonly accepted body of knowledge on market structure with network externalities, based on which one could evaluate deviations toward anti-competitive behavior. Third, the legal system has tremendous inertia to new ideas and models. Fourth, the legal system is ill-equipped to deal with complex technical matters. Fifth, given all these facts, lawyers on both sides find it easier to fight the issues on well-trodden ground even if the problems are really of a different nature. It is as if there is a dispute between two parties in the middle of a heavily forested area, but the lawyers of both parties fight it as if the dispute happened on the open plains, because they know the way disputes on the plains are resolved while the law of dispute resolution in forests has yet to be established.

I hope that, with further academic analysis of antitrust issues, when the next major New Economy antitrust case appears, there will be a deeper understanding and application of the economics of networks and of the way the law should apply to network industries.

\section{NOTES}

* Stern School of Business, New York University, New York, NY 10012,(212)998-0864, fax (212)995-4218, http://www.stern.nyu.edu/networks/, email: neconomi@stern.nyu.edu.

1. More precisely, the law of demand is true for normal goods, that is, for goods for which an increase in income leads to a higher quantity of sales. For inferior goods an increase in income leads to a lower quantity of sales. If this effect is strong enough, the possibility of a Giffen good arises where sales increase as prices increase. Giffen goods are truly exceptional and rarely observed.

2. The pricing schemes used vary considerably depending on the telecommunications service. Traditionally, in fixed networks, in most places in the United States, local calls are free with a local connection that requires a fixed monthly fee. Long-distance subscribers were traditionally charged only for outgoing calls. In the last two decades 800 , $866,877,888$-prefix 'toll free' services allow for no charge to the calling party, while 900 prefix services allow the receiving party to charge a positive price. In wireless cellular and PCS telecommunications, United States subscribers pay for both incoming and outgoing calls, while in most of the rest of the world, wireless subscribers pay only for outgoing calls. On the Internet, retail subscribers pay a flat fee irrespective of the amount of time they use the service, the number of bits exchanged, whether they are incoming or 
outgoing, and irrespective of the destination. Similarly, Internet service providers buy backbone connectivity at rates that depend just on the size of the pipe they utilize and irrespective of whether they are incoming or outgoing, and of the destination.

3. It is anecdotally known that Cantor Fitzgerald, which has a 70 per cent market share in the secondary market for US government 30 year bonds, offered to Salomon (the largest 'primary dealer' and trader of US bonds) prices equal to one tenth to one fifth of those charged to small traders. This is consistent with profit maximization by Cantor Fitzgerald because of the liquidity (network effect) brought to the market by Salomon which is by far the largest buyer ('primary dealer') in the auctions of US government bonds.

4. For a detailed discussion, see Economides and Himmelberg (1995).

5. If the distribution of the willingness to pay is distributed away from 0 , an industry with network effects exhibits the finiteness property (Shaked and Sutton 1983), with a finite maximum number of active firms despite positive profits.

6. An often-cited example on path dependence is the prevalence of the QWERTY keyboard despite claims of more efficient function by the alternative Dvorak keyboard. For many business applications, and for antitrust purposes, the QWERTY example is not crucial because there was no significant strategic business interest in the success of either design.

7. AT\&T claimed that the main reason for its refusal to interconnect was the low technical standards of the independents, as well as incompatibilities, that would jeopardize AT\&T's network after interconnection. While there is some truth to those claims, it is unlikely that they applied to all independents. Moreover, once acquired by AT\&T, independents were interconnected with AT\&T's network, after some modifications. This shows that the refusal to interconnect was mainly a strategic and commercial decision rather than a technical one.

8. This is not just a theoretical possibility. Telecom New Zealand ('TNZ'), operating in an environment of weak antitrust and regulatory intervention (so-called 'light-handed regulation') offered such high termination fees that the first entrant into local telecommunications, Clear, survives only by refusing to pay interconnection fees to TNZ, while the second entrant, BellSouth New Zealand exited the local telecommunications market.

9. For example, one can think of A as a computer operating system, and B as an application. OS manufacturers can and do embed software routines that are useful to application software developers since they reduce the cost of writing applications.

10. See Economides and Siow (1988) for a discussion of the benefits of B2B and other exchanges.

11. For a discussion of the Microsoft case, see Economides (2001a, 2001b, 2002) and http://www.stern.nyu.edu/networks/.

\section{REFERENCES}

Economides, Nicholas (1996), 'The economics of networks', International Journal of Industrial Organization, 16 (4), 675-99.

Economides, Nicholas (1998), 'The incentive for non-price discrimination by an input monopolist', International Journal of Industrial Organization, 16 (May 1998), 271-84.

Economides, Nicholas (1999), 'The Telecommunications Act of 1996 and its impact', Japan and the World Economy, 11, 455-83.

Economides, Nicholas (2001a), 'The Microsoft antitrust case', Journal of Industry, Competition and Trade: From Theory to Policy, 1 (1), 7-39.

Economides, Nicholas (2001b), 'The Microsoft antitrust case: rejoinder', Journal of Industry, Competition and Trade: From Theory to Policy, 1 (1), 71-9.

Economides, Nicholas (2002), 'Amicus brief of Nicholas S. Economides on the revised proposed final judgment in the Microsoft case', submitted to the United 
States Department of Justice, available at http://www.usdoj.gov/atr/cases/ ms_tuncom/major/mtc-00022465.htm.

Economides, Nicholas (2003), 'The tragic inefficiency of M-ECPR', in A. Shampine (ed.), Down to the Wire: Studies in the Diffusion and Regulation of Telecommunications Technologies, New York: Nova Science Publishers, pp. $142-54$.

Economides, Nicholas and Fredrick Flyer (1998), 'Compatibility and market structure for network goods', discussion paper EC-98-02, Stern School of Business, New York. University, available at http://www.stern.nyu.edu/networks/98-02.pdf.

Economides, Nicholas and Charles Himmelberg (1995), 'Critical mass and network evolution in telecommunications', in Gerard W. Brock (ed.), Toward a Competitive Telecommunications Industry: Selected Papers from the 1994 Telecommunications Policy Research Conference, Mahwah, NJ: Lawrence Erlbaum Association, pp. 47-63.

Economides, Nicholas and Aloysius Siow (1988), 'The division of markets is limited by the extent of liquidity', American Economic Review, 78 (1), 108-21.

Economides, Nicholas and Lawrence J. White (1994), 'Networks and compatibility: implications for antitrust', European Economic Review, 38, 651-62.

Economides, Nicholas and Lawrence J. White (1995), 'Access and interconnection pricing: how efficient is the efficient component pricing rule?', Antitrust Bulletin, XL (3), 557-79.

Economides, Nicholas and Lawrence J. White (1998), 'The inefficiency of the ECPR yet again: a reply to Larson', Antitrust Bulletin, XLIII (2), 429-44.

Economides, Nicholas, Giuseppe Lopomo and Glenn Woroch (1996a), 'Regulatory pricing policies to neutralize network dominance', Industrial and Corporate Change, 5 (4), 1013-28.

Economides, Nicholas, Giuseppe Lopomo and Glenn Woroch (1996b), 'Strategic commitments and the principle of reciprocity in interconnection pricing', discussion paper EC-96-13, Stern School of Business, New York University, available from http://www.stern.nyu.edu/networks/96-13.pdf.

Posner, Richard A. (2000), 'Antitrust in the New Economy', Tech Law Journal, at http://www.techlawjournal.com/atr/20000914posner.asp.

Shaked, Avner and John Sutton (1983), 'Natural oligopolies', Econometrica, 51, 1469-84. 